\title{
Antibiotic resistance and genetic diversity of Shigella sonnei isolated from patients with diarrhoea between 1999 and 2003 in Bangladesh
}

\begin{abstract}
Correspondence
Kaisar A. Talukder

kaisar@icddrb.org
\end{abstract}

Received 23 March 2006

Accepted 29 May 2006

\author{
Kaisar A. Talukder, Zhahirul Islam, Dilip K. Dutta, M. Aminul Islam, \\ Bijay K. Khajanchi, Ishrat J. Azmi, Mohd S. Iqbal, M. A. Hossain, \\ A. S. G. Faruque, G. Balakrish Nair and David A. Sack \\ ICDDR, B, Centre for Health and Population Research, GPO Box-128, Dhaka-1000, \\ Bangladesh
}

\begin{abstract}
Shigella sonnei is a significant cause of diarrhoeal infection in both developing and industrialized countries. From 1999 to 2003, 445 strains of Shigella sonnei were isolated from patients admitted to the diarrhoea treatment centre of the International Center for Diarrhoeal Disease Research, Bangladesh. More than $60 \%$ of the isolates were resistant to nalidixic acid, $89 \%$ to sulfamethoxazole-trimethoprim and $9.5 \%$ to ampicillin. In addition, $4 \%$ of strains were resistant to multiple antibiotics $\left(\mathrm{Amp}^{\mathrm{R}} \mathrm{Tet}^{\mathrm{R}} \mathrm{Sxt}^{\mathrm{R}} \mathrm{Str}^{\mathrm{R}}\right.$ ) and $4 \cdot 2 \%$ of strains were sensitive to all antibiotics tested. None of the strains were positive for the set 1 gene, whereas $46 \%$ were positive for the sen gene. Forty-six per cent of the strains (stored at $-70^{\circ} \mathrm{C}$ ) harboured the $120 \mathrm{MDa}$ invasive plasmid and representative strains produced keratoconjunctivitis in the guinea pig eye. In addition, three plasmids of approximately 5, 1.8 and 1.4 MDa were found to be present in more than $90 \%$ of the strains. A self-transmissible, middle-ranged plasmid (35-80 MDa) carrying the multiple antibiotic resistance gene was found in some strains. PFGE analysis of the strains identified five unique types with many subtypes, which were characterized into four unique types by ribotyping analysis. It can be concluded that endemic strains of Shigella sonnei isolated from patients in Bangladesh are diverse in their genetic pattern.
\end{abstract}

\section{INTRODUCTION}

Bacillary dysentery caused by Shigella species is a serious public health problem in both developing and industrialized countries (Lee et al., 2000; Pan, 1996) and outbreaks due to Shigella infection are difficult to control because of their low infectious dose (Dupont et al., 1989). Increased numbers of cases in a community that appear to be sporadic may in fact be due to unrecognized outbreaks (Litwin et al., 1997). Shigellosis is caused by any of the four species of Shigella, namely Shigella dysenteriae, Shigella flexneri, Shigella boydii and Shigella sonnei. Of these, Shigella sonnei is the most prevalent $(77 \%)$ species in industrialized countries and the second most prevalent in developing countries, followed by Shigella flexneri (Kotloff et al., 1999). Shigellosis is endemic in Bangladesh and accounts for $20 \%$ of deaths related to diarrhoea among children (Victora et al., 1993). Fatality rates due to Shigella sonnei infection are highest among children less than 1 year old in Bangladesh (Bennish et al., 1990). Species-wise incidence of shigellosis including that caused by Shigella sonnei in Bangladesh was reported in a previous study (Talukder et al., 2003b). Unlike developed and industrialized countries, an extensive study on Shigella sonnei in terms of clonal diversity and antimicrobial resistance pattern has not been undertaken in the developing world and particularly in Bangladesh. In the past, several conventional typing methods were used for epidemiological subtyping of Shigella sonnei (Lin \& Chang, 1992; Morris \& Wells, 1974; Pruneda \& Farmer, 1977) based on phenotypic properties, but the usefulness of these techniques is now limited, because of the availability of more discriminatory molecular typing methods, including plasmid profiling, ribotyping and PFGE. The aim of this study was to determine the aetiological significance of Shigella sonnei among patients with diarrhoea in Bangladesh and to determine its clonal distribution based on phenotypic and genotypic characteristics.

\section{METHODS}

Strains. One hundred and eighty-four clinical strains of Shigella sonnei were randomly selected from 445 strains isolated from patients attending the Dhaka treatment centre operated by the International Center for Diarrhoeal Disease Research, Bangladesh (ICDDR, B), in Bangladesh between January 1999 and December 2003. The strains were isolated and identified in the Clinical Microbiology Laboratory, according to standard microbiological and biochemical methods (World Health Organization, 1987). The 
strains were grown in trypticase soy broth containing $0.3 \%$ yeast extract and stored at $-70^{\circ} \mathrm{C}$ after addition of $15 \%$ glycerol. Shigella flexneri 2a YSH6000 (Sasakawa et al., 1986) and an Escherichia coli (ATCC 25922) strain lacking the $140 \mathrm{MDa}$ invasive plasmid and sensitive to all antibiotics were used as positive and negative controls, respectively, in the Sereny test and for PCR. E. coli K-12 $\left(\mathrm{Lac}^{+}, \mathrm{F}^{-}\right)$, resistant to nalidixic acid, was used as the recipient in the conjugation experiments (Haider et al., 1989).

Serotyping. Serotypes were determined by using a commercially available antisera kit (Denka Seiken). Strains were subcultured on MacConkey agar (Difco) plates and serological reactions were performed after about $18 \mathrm{~h}$ of incubation by using the slide agglutination test, as described previously (Talukder et al., 2001).

Biochemical characterization. The biochemical reactions of the strains were determined by using standard methods (World Health Organization, 1987).

Antimicrobial susceptibility. Bacterial susceptibility to antimicrobial agents was determined by using the disc diffusion method, as recommended by the Clinical and Laboratory Standards Institute (CLSI, 2004) with commercial antimicrobial discs (Oxoid). The antibiotic discs used in this study were ampicillin (Amp; $10 \mu \mathrm{g}$ ), tetracycline (Tet; $30 \mu \mathrm{g})$, mecillinam $(25 \mu \mathrm{g})$, nalidixic acid $(\mathrm{Nal}$; $30 \mu \mathrm{g}$ ), sulfamethoxazole-trimethoprim (Sxt; $25 \mu \mathrm{g}$ ), ciprofloxacin $(5 \mu \mathrm{g})$, norfloxacin $(10 \mu \mathrm{g})$, ofloxacin $(5 \mu \mathrm{g})$, azithromycin $(15 \mu \mathrm{g})$ and ceftriaxone $(30 \mu \mathrm{g})$. E. coli ATCC 25922 and Staphylococcus aureus ATCC 25923 were used as control strains for the susceptibility tests.

Test for invasiveness and detection of Shigella enterotoxin genes. Nine representative strains were subjected to the keratoconjunctivitis assay in the guinea pig eye, according to the procedures described by Mackel et al. (1961) and Sereny (1957). The experimental procedures were approved by the animal experimentation ethics committee of ICDDR, B and were in accordance with ethical guidelines for the care of animals. The same bacterial colony was used for the preparation of template DNA for PCR for set 1 and sen genes. The primer sets and PCR conditions used were those described by Vargas et al. (1999).

Plasmid profile analysis. Plasmid DNA was prepared according to the alkaline lysis method of Kado \& Liu (1981), with some modifications as described previously (Talukder et al., 2002). The molecular mass of the unknown plasmid DNA was assessed by comparing the mobility with that of plasmids of known molecular mass (Haider et al., 1989). Plasmids present in E. coli PDK-9, R1, RP 4 , Sa and V517 described previously (Talukder et al., 2002) were used as molecular mass standards.

Determination of resistance factors. Conjugation experiments between multi-drug resistant $\left(\mathrm{Amp}^{\mathrm{R}} \mathrm{Sxt}^{\mathrm{R}} \mathrm{Tet}^{\mathrm{R}} \mathrm{Str}^{\mathrm{R}}\right)$ Shigella sonnei (K-656 and K-386) strains and recipient E. coli $\mathrm{K}-12\left(\mathrm{Nal}^{\mathrm{R}}, \mathrm{Lac}^{+}\right.$, $\mathrm{F}^{-}$) were carried out according to the method described previously (Munshi et al., 1987). Transconjugant colonies were selected on MacConkey agar plates containing nalidixic acid $\left(30 \mu \mathrm{g} \mathrm{ml}^{-1}\right)$ and ampicillin $\left(50 \mu \mathrm{g} \mathrm{ml}^{-1}\right)$. Plasmid analysis and antimicrobial susceptibility tests of the transconjugants were carried out. Determination of transfer frequency and curing of the resistance plasmid were performed as described previously (Munshi et al., 1987).

Ribotyping. Total cellular DNA was extracted and purified according to the procedures described previously (Talukder et al., 2002). DNA was digested with HindIII overnight at $37^{\circ} \mathrm{C}$ according to the instructions of the manufacturer (Gibco-BRL) and separated by gel electrophoresis in $0.9 \%$ agarose in Tris-borate EDTA (TBE) buffer for $18 \mathrm{~h}$ at a constant $35 \mathrm{~V}$. Southern blotting to a positively charged nylon membrane (Amersham Pharmacia Biotech) was performed with a vacuum pump unit (Bio-Rad) and the DNA fragments were fixed to the membrane by exposure to UV light for 3 min. A digoxigenin (DIG)-labelled cDNA probe specific for the $16 \mathrm{~S}$ rDNA (Kariyama et al., 2000) was constructed, according to the procedure described previously (Talukder et al., 2002). Hybridization of the membrane with the DIG-labelled probe for $18 \mathrm{~h}$ at $42^{\circ} \mathrm{C}$ and development of the membrane with antiDIG-alkaline phosphatase were performed according to the instructions provided in the DIG DNA labelling and detection kit (Roche Diagnostics). Results were documented by photographing the membrane.

PFGE. Intact, agarose-embedded chromosomal DNA from clinical isolates of Shigella sonnei was prepared and PFGE was performed using a contour-clamped homogeneous electric field (CHEF-DRII) apparatus (Bio-Rad), according to procedures described previously (Albert et al., 1997; Okada et al., 1991; Talukder et al., 1999, 2003a) and by Brian et al. (1993), but with different pulse times, 1-10 s for $10 \mathrm{~h}, 3-28 \mathrm{~s}$ for $10 \mathrm{~h}, 3-35 \mathrm{~s}$ for $5 \mathrm{~h}$ and $5-70 \mathrm{~s}$ for $15 \mathrm{~h}$. Genomic DNA was digested with $\mathrm{XbaI}$ (Gibco-BRL). The restriction fragments were separated by using a CHEF-DRII system apparatus in $1 \%$ pulsed-field certified agarose in $0.5 \times$ TBE buffer. The gel was stained, destained and photographed using a gel documentation system, according to procedures described previously (Talukder et al., 2002). The DNA size standards used were a bacteriophage lambda ladder ranging from 48.5 to $1000 \mathrm{~kb}$ (Bio-Rad) and Salmonella Branderup chromosomal DNA ranging from $15 \cdot 8$ to $917 \mathrm{~kb}$. Band patterns were established by the criteria described by Tenover et al. (1995).

\section{RESULTS}

\section{Biochemical characterization}

All the 184 representative strains of Shigella sonnei were negative for indole production and positive for arabinose, mannitol, mannose, trehalose, maltose, rhamnose and ornithine fermentation. About $62 \%(n=114)$ of the strains showed raffinose fermentation, but none of the strains were positive for utilization of sodium acetate, sorbitol, dulcitol, xylose, arginine or lysine. Two different biotypes (BT1 and BT2) were found based on raffinose fermentation (Table 1).

\section{Antimicrobial susceptibility}

More than $60 \%$ of the strains in the present study were resistant to nalidixic acid, $89 \%$ to sulfamethoxazoletrimethoprim and $9.5 \%$ to ampicillin. In addition, $4 \%$ $(n=18)$ of strains were found to be resistant to multiple antibiotics $\left(\mathrm{Amp}^{\mathrm{R}} \mathrm{Tet}^{\mathrm{R}} \mathrm{Sxt}^{\mathrm{R}} \mathrm{Str}^{\mathrm{R}}\right)$ and $4 \cdot 2 \%(n=19)$ were sensitive to all antibiotics tested. None of the strains were resistant to ciprofloxacin, norfloxacin, ofloxacin, mecillinam, azithromycin or ceftriaxone.

\section{Test for invasiveness and detection of Shigella enterotoxin genes}

Five representative strains containing a $120 \mathrm{MDa}$ invasive plasmid were positive for keratoconjunctivitis in the guinea pig eye. In contrast, the representative four strains that did not contain a $120 \mathrm{MDa}$ plasmid were found to be negative in the Sereny test. The Shigella enterotoxin 1 (set1) gene was not present in the strains of Shigella sonnei tested, whereas 
Table 1. Characteristics of Shigella sonnei strains isolated in Bangladesh

Amp, Ampicillin; Nal, nalidixic acid; Sxt, trimethoprim-sulfamethoxazole.

\begin{tabular}{|c|c|c|c|c|}
\hline No. of strains tested & PFGE pattern & Ribotype & Biotype $^{\star}$ & Antibiogram (no. of strains) \\
\hline 27 & Al & R1 & BT1 & $\mathrm{Sxt}^{\mathrm{R}} \mathrm{Nal}^{\mathrm{R}}(17), \mathrm{Sxt}^{\mathrm{R}}(10)$ \\
\hline 28 & A2 & $\mathrm{R} 1$ & BT1 & $\mathrm{S}_{x t^{\mathrm{R}}} \mathrm{Nal}^{\mathrm{R}}(26), \mathrm{Sxt}^{\mathrm{R}}$ (2) \\
\hline 20 & A3 & R1 & BT1 & $\mathrm{Sxt}^{\mathrm{R}}(9), \mathrm{Sxt}^{\mathrm{R}} \mathrm{Nal}^{\mathrm{R}}(11)$ \\
\hline 2 & A4 & $\mathrm{R} 1$ & BT1 & $\mathrm{Sxt}^{\mathrm{R}} \mathrm{Nal}^{\mathrm{R}}(2)$ \\
\hline 2 & A5 & $\mathrm{R} 1$ & BT1 & $\mathrm{Amp}^{\mathrm{R}} \mathrm{Sxt}^{\mathrm{R}}(2)$ \\
\hline 4 & A6 & $\mathrm{R} 1$ & BT1 & $\mathrm{Amp}^{\mathrm{R}} \mathrm{Sxt}^{\mathrm{R}}(2), \mathrm{Sxt}^{\mathrm{R}} \mathrm{Nal}^{\mathrm{R}}(2)$ \\
\hline 4 & A7 & $\mathrm{R} 1$ & BT1 & $\mathrm{Sxt}^{\mathrm{R}} \mathrm{Nal}^{\mathrm{R}}(4)$ \\
\hline 1 & A8 & $\mathrm{R} 1$ & BT1 & $\mathrm{Sxt}^{\mathrm{R}}$ \\
\hline 2 & B1 & $\mathrm{R} 2$ & BT2 & All sensitive (2) \\
\hline 2 & B2 & $\mathrm{R} 2$ & BT2 & All sensitive (2) \\
\hline 2 & $\mathrm{C}$ & R3 & BT2 & All sensitive (2) \\
\hline 2 & $\mathrm{D}$ & $\mathrm{R} 4$ & BT2 & All sensitive (2) \\
\hline 2 & E1 & $\mathrm{R} 1$ & BT2 & All sensitive (2) \\
\hline 1 & E2 & $\mathrm{R} 1$ & BT2 & All sensitive (1) \\
\hline 1 & E3 & $\mathrm{R} 1$ & BT2 & All sensitive (1) \\
\hline
\end{tabular}

${ }^{*}$ BT1: fermentation of ornithine, lactose, arabinose, mannose, mannitol, trehalose, raffinose and maltose; BT2: fermentation of ornithine, lactose, arabinose, mannose, mannitol, trehalose and maltose.

the Shigella enterotoxin 2 gene (sen) was present in all strains containing a 120 MDa plasmid.

\section{Plasmid profile analysis}

Heterogeneous plasmid profiles ranging in size from approximately 120 to $1 \cdot 4 \mathrm{MDa}$ were found among the strains. Three plasmids of approximately 5, 1.8 and 1.4 MDa in size were present in more than $90 \%$ of the strains and were considered to be the core plasmids of Shigella sonnei (Fig. 1). Interestingly, $54 \%$ of the strains ( $n=100$ ) isolated during the period 1999-2003 were found to lack the $120 \mathrm{MDa}$ invasive plasmid. A middle-ranged plasmid of approximately 35-80 MDa in size was found in $12 \%(n=22)$ of the strains.

\section{Determination of resistance factor}

Two strains designated K-656 and K-386 with the resistance pattern $\mathrm{Amp}^{\mathrm{R}} \mathrm{Tet}^{\mathrm{R}} \mathrm{Sxt}^{\mathrm{R}} \mathrm{Str}^{\mathrm{R}}$ and containing an $80 \mathrm{MDa}$ plasmid were selected for conjugation with E. coli K-12 $\left(\mathrm{Lac}^{+}\right.$and $\left.\mathrm{Nal}^{\mathrm{R}}\right)$. An $80 \mathrm{MDa}$ plasmid was transferred with the multiple antibiotic resistance determinants $\left(\mathrm{Amp}^{\mathrm{R}} \mathrm{Tet}^{\mathrm{R}}\right.$ $\mathrm{Sxt}^{\mathrm{R}}$ ) to the recipient cells via conjugation. The transfer frequency was very high for all the transmissible plasmids (Table 2). The transmissible resistance determinants were confirmed by curing the transconjugants (Table 2).

\section{Ribotyping}

Hybridization of HindIII-digested chromosomal DNA with the $16 \mathrm{~S}$ rDNA probe revealed a total of seven to nine fragments ranging in size from 5 to $15 \mathrm{~kb}$ in all the representative strains of Shigella sonnei (Fig. 2). Four unique rRNA gene restriction patterns, ribotypes R1, R2, R3 and R4, were obtained among the representative strains.

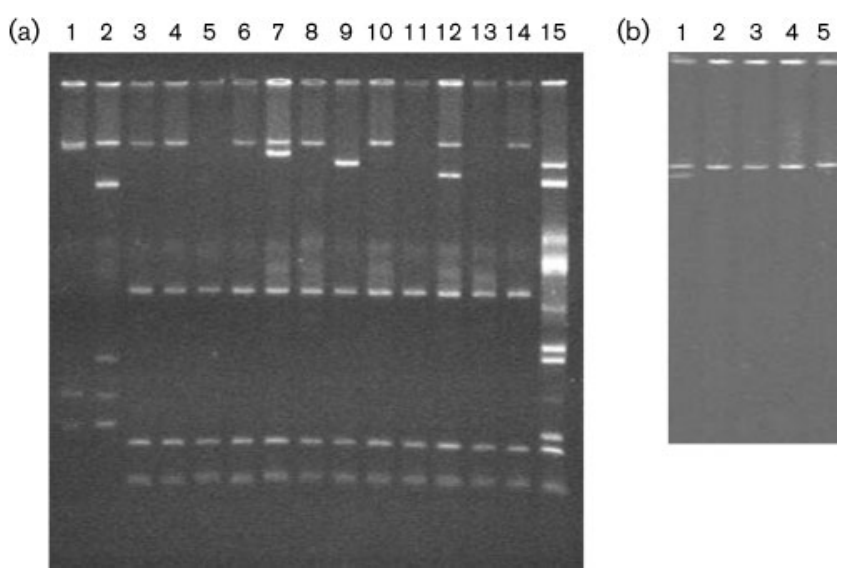

Fig. 1. (a) Agarose gel electrophoresis of plasmid DNA showing the representative patterns among isolates of Shigella sonnei. Lanes: 1, E. coli PDK-9 (marker); 2, S. sonnei K-476; 3, S. sonnei K-544; 4, S. sonnei K-548; 5, S. sonnei K-564; 6, S. sonnei K-567; 7, S. sonnei K-586; 8, S. sonnei K-1038; 9, S. sonnei K-1051; 10, S. sonnei K-1036; 11, S. sonnei K$1075 ; 12, S$. sonnei KD-446; 13, S. sonnei KD-462; 14, S. sonnei KD-226; 15, E. coli V517+R1. (b) Agarose gel electrophoresis of plasmid DNA of Shigella sonnei strains run for 16 h. Lanes: 1, E. coli PDK-9 (marker); 2, S. sonnei KD-412; 3, S. sonnei $\mathrm{K}-544 ; 4$, S. sonnei $\mathrm{K}-567 ; 5$, S. flexneri YSH6000. 
Table 2. Results of conjugation between two strains of Shigella sonnei and E. coli K-12

Amp, Ampicillin; Nal, nalidixic acid; Str, streptomycin; Sxt, trimethoprim-sulfamethoxazole; Tet, tetracycline.

\begin{tabular}{|c|c|c|c|c|c|c|c|}
\hline \multirow[t]{2}{*}{ Strain no. } & \multicolumn{2}{|c|}{ Parent strain } & \multicolumn{2}{|c|}{ Transconjugant } & \multirow{2}{*}{$\begin{array}{l}\text { Transfer frequency } \\
\text { of R-plasmid }\end{array}$} & \multicolumn{2}{|c|}{ Cured strain } \\
\hline & Resistance pattern & $\begin{array}{l}\text { Plasmid profile } \\
\text { (MDa) }\end{array}$ & $\begin{array}{c}\text { Resistance } \\
\text { pattern }\end{array}$ & $\begin{array}{c}\text { Plasmid profile } \\
\text { (MDa) }\end{array}$ & & $\begin{array}{c}\text { Resistance } \\
\text { pattern }\end{array}$ & $\begin{array}{c}\text { Plasmid } \\
\text { profile } \\
\text { (MDa) }\end{array}$ \\
\hline K-656 & Amp Sxt Str Tet & $140,80,5 \cdot 0,1 \cdot 8,1 \cdot 4$ & Amp Sxt Tet Nal & 80 & $4 \cdot 0 \times 10^{-4}$ & $\mathrm{Nal}$ & No plasmid \\
\hline K-386 & Amp Sxt Str Tet & $\begin{array}{c}140,80,2 \cdot 8,4 \cdot 0,2 \cdot 1 \\
1 \cdot 8,1 \cdot 0\end{array}$ & Amp Sxt Tet Nal & 80 & $1 \cdot 2 \times 10^{-4}$ & $\mathrm{Nal}$ & No plasmid \\
\hline
\end{tabular}

\section{PFGE}

Of 184 strains, 100 were randomly selected for PFGE analysis. XbaI-digested chromosomal DNA of these strains yielded 15-24 reproducible DNA fragments, ranging in size from approximately 20 to $485 \mathrm{~kb}$ (Fig. 3). These strains yielded five unique PFGE types designated A, B, C, D and E with numerous subtypes (Fig. 3), of which $88 \%$ of the strains belonged to type A, $4 \%$ belonged to types $\mathrm{B}$ and $\mathrm{E}$ each and $2 \%$ belonged to types $C$ and $D$ each (Fig. 3). Type A was further subdivided into five subtypes (A1-A5), and types B and E into two (B1 and B2) and three (E1-E3) subtypes, respectively.

\section{DISCUSSION}

We examined 184 clinical strains of Shigella sonnei that were isolated between January 1999 and December 2003, using biochemical characterization, antimicrobial susceptibility testing, plasmid profile analysis, PFGE and ribotyping, in order to define the aetiological significance of endemic shigellosis due to infection by Shigella sonnei in Bangladesh. According to our previous study, during the period 1999-2002, each year about $8 \%$ of the total number of cases of shigellosis were caused by infection due to Shigella

\section{$\begin{array}{llllllllllllll}1 & 2 & 3 & 4 & 5 & 6 & 7 & 8 & 9 & 10 & 11 & 12 & 13 & 14\end{array}$}

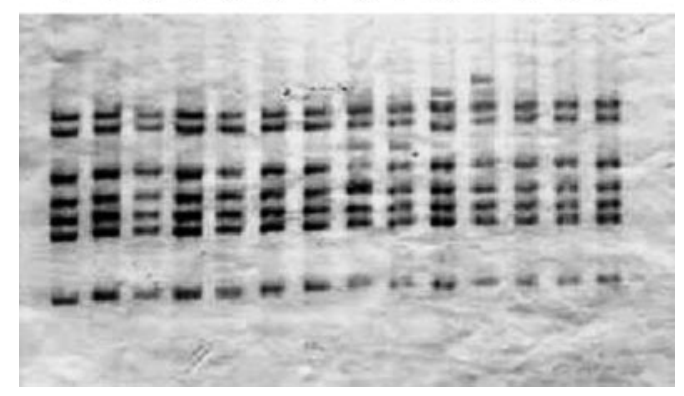

Fig. 2. Ribotyping for the representative strains of Shigella sonnei. Lanes: 1, K-655 (R1); 2, KD-446 (R1); 3, K-633 (R1); 4, K-656 (R1); 5, KD-412 (R1); 6, KD-501 (R1); 7, KD-632 (R1); 8, K-701 (R2); 9, K-631 (R2); 10, K-366 (R3); 11, K368 (R4); 12, K-436 (R1); 13, KD-223 (R1); 14, K-436 (R1). sonnei (Talukder et al., 2003b). A similar trend was observed in 2003. The first step in the characterization scheme for all strains in the present study was biochemical reaction pattern, in which we did not observe any significant change from the typical reactions of Shigella sonnei described by Ewing (1986). Based on the biochemical reaction profiles, strains could not be divided into different clonal groups.

Resistance of Shigella species to commonly used antimicrobial agents has been increasing in Bangladesh (Hossain et al., 1998). Ampicillin or trimethoprim combined with sulfamethoxazole has been used to treat shigellosis during the past two decades. However, a high proportion of Shigella sonnei strains were resistant to these antibiotics (Kim et al.,

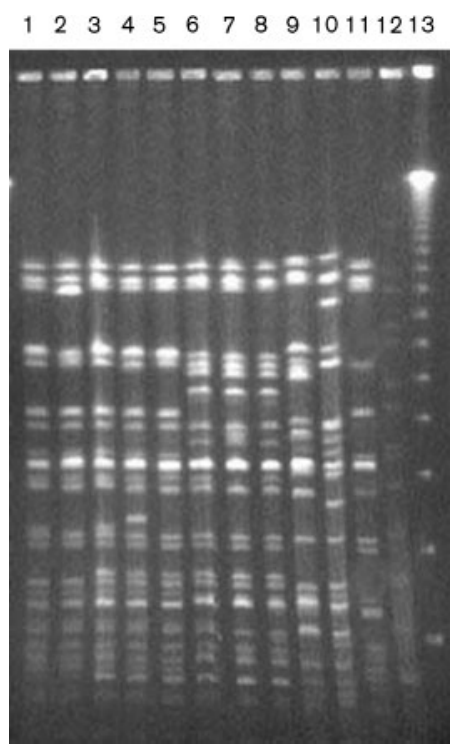

Fig. 3. PFGE banding patterns of $X b$ bal-digested chromosomal DNA of representative strains of Shigella sonnei. Lanes: $1, \mathrm{~K}-$ 655 (PFGE type A1); 2, KD-446 (PFGE type A2); 3, K-633 (PFGE type A3); 4, K-656 (PFGE type A4); 5, KD-412 (PFGE type A5); 6, K-564 (PFGE type B1); 7, K-701 (PFGE type B2); 8, K-631 (PFGE type B1); 9, K-366 (PFGE type C); 10, K-368 (PFGE type D); 11, K-436 (PFGE type E); 12, Salmonella Branderup (marker); 13, lambda ladder (marker). 
2002). In this study, none of the strains were found to be resistant to ciprofloxacin, norfloxacin, ofloxacin, mecillinam, azithromycin or ceftriaxone.

Plasmid profile analysis has been applied extensively in epidemiological investigations of various enteric pathogens, particularly if there is a wide range of stable plasmids present in the bacterial population (Shahid et al., 1985; Surdeanu et al., 2000; Prado et al., 1987). Shigella sonnei usually harbours a heterogeneous population of plasmids, which may range in number from two to as many as 10 (Haider $e t$ al., 1989) and from 1.4 to $120 \mathrm{MDa}$ in molecular mass. Of 184 strains, $54 \%$ did not harbour the $120 \mathrm{MDa}$ plasmid, which carries the major determinants for invasiveness. One of the possible explanations for this result might be the loss of the $120 \mathrm{MDa}$ plasmid because of: (i) prolonged storage of the strains at $-70^{\circ} \mathrm{C}$; and (ii) repeated subculturing of the strains, which has also been described previously by Vargas et al. (1999). In addition to the large plasmid, about $90 \%$ of the strains contained three plasmids of approximately $5,1 \cdot 8$ and $1.4 \mathrm{MDa}$ in size. In order to validate this cluster of plasmids as core plasmids of Shigella sonnei, it was compared with the plasmid profiles of all the serotypes and subserotypes of Shigella species (data not shown). The cluster of these three plasmids was found to be unique to Shigella sonnei and did not match the plasmid profiles of any of the existing Shigella serotypes.

Conjugative plasmids encoding resistance to antibiotics have been detected in numerous studies on Shigella sonnei (DeLappe et al., 2003). The experiment in the present study demonstrated that middle-range plasmids were self-transmissible, conferring resistance to ampicillin, tetracycline and trimethoprim-sulfamethoxazole. The co-transfer of streptomycin resistance was not observed, suggesting that the resistance determinants of this antibiotic in Shigella sonnei are not associated with the conjugative plasmids.

Invasiveness is an important property of pathogenic Shigella species. Shigella flexneri produces an enterotoxin (Kinsey et al., 1976; Rout et al., 1975), mainly of two types, Shigella enterotoxin 1 (ShET-1) and Shigella enterotoxin 2 (ShET-2). In our study, ShET-1 was not found in Shigella sonnei, confirming previous results (Nataro et al., 1995). In contrast to the study of Vargas et al. (1999), which showed that $100 \%$ of Shigella sonnei strains isolated between 1996 and 1998 were positive for ShET-2 (sen), we found that only $46 \%$ of Shigella sonnei strains in this study were positive for this gene. In addition, a correlation between the presence of the $120 \mathrm{MDa}$ plasmid and the sen gene was observed.

PFGE and ribotyping have been used more widely to determine the genetic diversity of various enteropathogens including Shigella sonnei (Hinojosa-Ahumada et al., 1991; Korpela et al., 1995; Pace et al., 1986). Applying these two techniques, we identified four ribotypes, R1, R2, R3 and R4, whereas five PFGE types (A, B, C, D and E) were found in the same set of strains of Shigella sonnei. Among these four ribotypes, one (R1) was shared by two different PFGE types
(A and E). The present study showed the poor discriminatory power of ribotyping for Shigella sonnei isolates, compared with PFGE. This finding is similar to previous reports on strains from Taiwan (Henry, 1991; Liu et al., 1995). However, ribotyping has been used successfully for epidemiological investigation of Shigella sonnei in Spain (Pace et al., 1986) and other countries (Hinojosa-Ahumada et al., 1991; Korpela et al., 1995). It is interesting to note here that PFGE type A belonged to biotype BT1 and all the other types (PFGE types B, C, D and E) belonged to biotype BT2 only. PFGE type A was found to be predominant, encompassing approximately $88 \%$ of the strains in the present study. A good correlation was observed between PFGE type, ribotype, antimicrobial resistance pattern and biotyping (Table 1). Strains that were resistant to single or multiple drugs belonged to PFGE type A, whereas strains that were sensitive to all antibiotics tested were more heterogeneous in PFGE type. Although Shigella sonnei is a more common problem in the developed and industrialized countries, this study underlines a significant burden of this pathogen in overall Shigella infections in Bangladesh, with strains of heterogeneous traits.

\section{ACKNOWLEDGEMENTS}

This study was funded by the United States Agency for International Development (USAID) under Cooperative Agreement No. HRN-A-0096-90005-00 and ICDDR, B, Centre for Health and Population Research, which is supported by countries and agencies that share its concern for the health problems of developing countries. Current donors providing unrestricted support include the aid agencies of the Governments of Australia, Bangladesh, Belgium, Canada, Japan, The Netherlands, the Kingdom of Saudi Arabia, Sweden, Sri Lanka, Switzerland and the USA. ICDDR, B acknowledges with gratitude the commitment of USAID and other donors to the Centre's research effort.

\section{REFERENCES}

Albert, M. J., Bhuiyan, N. A., Talukder, K. A., Faruque, A. S. G., Nahar, S., Faruque, S. M., Ansaruzzaman, M. \& Rahman, M. (1997). Phenotypic and genotypic changes in Vibrio cholerae 0139 Bengal. J Clin Microbiol 35, 2588-2592.

Bennish, M. L., Harris, J. R., Wojtyniak, B. J. \& Struelens, M. (1990). Death in shigellosis: incidence and risk factors in hospitalized patients. J Infect Dis 161, 500-506.

Brian, M. J., Van, R., Townsend, I., Murray, B. E., Cleary, T. G. \& Pickering, L. K. (1993). Evaluation of the molecular epidemiology of an outbreak of multiply resistant Shigella sonnei in a day-care center by using pulsed-field gel electrophoresis and plasmid DNA analysis. J Clin Microbiol 31, 2152-2156.

Clinical and Laboratory Standards Institute (2004). Performance standards for antimicrobial susceptibility testing; approved standard, 14th edn, document M100-S14. Wayne, PA: Clinical and Laboratory Standards Institute.

DeLappe, N., O'Halloran, F., Fanning, S., Corbett-Feeney, G., Cheasty, T. \& Cormican, M. (2003). Antimicrobial resistance and genetic diversity of Shigella sonnei isolates from Western Ireland, an area of low incidence of infection. J Clin Microbiol 41, 1919-1924. 
DuPont, H. L., Levine, M. M., Hornick, R. B. \& Formal, S. B. (1989). Inoculum size in shigellosis and implications for expected mode of transmission. J Infect Dis 159, 1126-1128.

Ewing, W. H. (1986). The genus Shigella. In Identification of Enterobacteriaceae, 4th edn, pp. 135-172. Edited by W. H. Ewing. New York: Elsevier.

Haider, K., Huq, M. I., Talukder, K. A. \& Ahmad, Q. S. (1989). Electropherotyping of plasmid DNA of different serotypes of Shigella flexneri isolated in Bangladesh. Epidemiol Infect 102, 421-428.

Henry, F. J. (1991). The epidemiologic importance of dysentery in communities. Rev Infect Dis 13 (Suppl 4), S238-S244.

Hinojosa-Ahumada, M., Swaminathan, B., Hunter, S. B., Cameron, D. N., Kiehlbauch, J. A., Wachsmuth, K. \& Strockbine, N. A. (1991). Restriction fragment length polymorphisms in rRNA operons for subtyping Shigella sonnei. J Clin Microbiol 29, 2380-2384.

Hossain, M. A., Rahman, M., Ahmed, Q. S., Malek, M. A., Sack, R. B. \& Albert, M. J. (1998). Increasing frequency of mecillinam-resistant Shigella isolates in urban Dhaka and rural Matlab, Bangladesh: a 6 year observation. J Antimicrob Chemother 42, 99-102.

Kado, C. I. \& Liu, S. T. (1981). Rapid procedure for detection and isolation of large and small plasmids. J Bacteriol 145, 1365-1373.

Kariyama, R., Mitsuhata, R., Chow, J. W., Clewell, D. B. \& Kumon, H. (2000). Simple and reliable multiplex PCR assay for surveillance isolates of vancomycin-resistant enterococci. J Clin Microbiol 38, 3092-3095.

Kim, K. S., Oh, J. Y., Jeong, Y. W., Cho, J. W., Park, J. C., Cho, D. T. \& Lee, J. C. (2002). Epidemiological typing and characterization of $d f r$ genes of Shigella sonnei isolates in Korea during the last two decades. J Microbiol Biotechnol 12, 106-113.

Kinsey, M. D., Formal, S. B., Dammin, G. J. \& Giannella, R. A. (1976). Fluid and electrolyte transport in Rhesus monkeys challenged intracecally with Shigella flexneri 2a. Infect Immun 14, 368-371.

Korpela, J., Karpanoja, P., Taipalinen, R. \& Siitonen, A. (1995). Subtyping of Shigella sonnei for tracing nosocomial transmission. J Hosp Infect 30, 261-266.

Kotloff, K. L., Winickoff, J. P., Ivanoff, B., Clemens, J. D., Swerdlow, D. L., Sansonetti, P. J., Adak, G. K. \& Levine, M. M. (1999). Global burden of Shigella infections: implications for vaccine development and implementation of control strategies. Bull World Health Organ 77, 651-666.

Lee, T.-M., Chang, L.-L., Chang, C.-Y., Wang, J.-C., Pan, T.-M., Wang, T.-K. \& Chang, S.-F. (2000). Molecular analysis of Shigella sonnei isolated from three well-documented outbreaks in school children. $J$ Med Microbiol 49, 355-360.

Lin, S.-R. \& Chang, S.-F. (1992). Drug resistance and plasmid profile of shigellae in Taiwan. Epidemiol Infect 108, 87-97.

Litwin, C. M., Leonard, R. B., Carroll, K. C., Drummond, W. K. \& Pavia, A. T. (1997). Characterization of endemic strains of Shigella sonnei by use of plasmid DNA analysis and pulsed-field gel electrophoresis to detect patterns of transmission. J Infect Dis 175, 864-870.

Liu, P. Y.-F., Lau, Y.-J., Hu, B.-S., Shyr, J.-M., Shi, Z.-Y., Tsai, W.-S., Lin, Y.-H. \& Tseng, C.-Y. (1995). Analysis of clonal relationships among isolates of Shigella sonnei by different molecular typing methods. J Clin Microbiol 33, 1779-1783.

Mackel, D. C., Langley, L. F. \& Venice, L. A. (1961). The use of guinea-pig conjunctivae as an experimental model for the study of virulence of Shigella organisms. Am J Hyg 73, 219-223.

Morris, G. K. \& Wells, J. G. (1974). Colicin typing of Shigella sonnei. Appl Microbiol 27, 312-316.
Munshi, M. H., Sack, D. A., Haider, K., Ahmed, Z. U., Rahaman, M. M. \& Morshed, M. G. (1987). Plasmid-mediated resistance to nalidixic acid in Shigella dysenteriae type 1. Lancet 2, 419-421.

Nataro, J. P., Seriwatana, J., Fasano, A., Maneval, D. R., Guers, L. D., Noriega, F., Dubovsky, F., Levine, M. M. \& Morris, J. G., Jr (1995). Identification and cloning of a novel plasmid-encoded enterotoxin of enteroinvasive Escherichia coli and Shigella strains. Infect Immun 63, $4721-4728$

Okada, N., Sasakawa, C., Tobe, T., Talukder, K. A., Komatsu, K. \& Yoshikawa, M. (1991). Construction of a physical map of the chromosome of Shigella flexneri $2 \mathrm{a}$ and the direct assignment of nine virulence-associated loci identified by Tn5 insertions. Mol Microbiol 5, 2171-2180.

Pace, N. R., Oslen, G. J. \& Woese, C. R. (1986). Ribosomal RNA phylogeny and the primary lines of evolutionary descent. Cell $\mathbf{4 5}$, 325-326 (in Chines).

Pan, T. M. (1996). Recent trends in the epidemiology of shigellosis. Taipei, Taiwan, Department of Health, Execute Yuan, Republic of China. Epidemiol Bull 12, 212-219 (in Chinese).

Prado, D., Murray, B. E., Cleary, T. G. \& Pickering, L. K. (1987). Limitations of using the plasmid pattern as an epidemiological tool for clinical isolates of Shigella sonnei. J Infect Dis 155, 314-316.

Pruneda, R. C. \& Farmer, J. J., III (1977). Bacteriophage typing of Shigella sonnei. J Clin Microbiol 5, 66-74.

Rout, W. R., Formal, S. B., Giannella, R. A. \& Dammin, G. J. (1975). Pathophysiology of Shigella diarrhoea in the Rhesus monkey: intestinal transport, morphological, and bacteriological studies. Gastroenterology 68, 270-278.

Sasakawa, C., Kamata, K., Sakai, T., Murayama, S. Y., Makino, S. \& Yoshikawa, M. (1986). Molecular alteration of the 140-megadalton plasmid associated with loss of virulence and Congo red binding activity in Shigella flexneri. Infect Immun 51, 470-475.

Sereny, B. (1957). Experimental keratoconjunctivitis Shigellosa. Acta Microbiol Acad Sci Hung 2, 367-376.

Shahid, N. S., Rahaman, M. M., Haider, K., Banu, H. \& Rahman, N. (1985). Changing pattern of resistant Shiga bacillus (Shigella dysenteriae type 1) and Shigella flexneri in Bangladesh. J Infect Dis 152, 1114-1119.

Surdeanu, M., Pencu, E., Tonciu, M., Mihai, I. \& Ciudin, L. (2000). Differentiation of Shigella strains by plasmid profile analysis, serotyping and phage typing. Roum Arch Microbiol Immunol 59, 103-117.

Talukder, K. A., Dutta, D. K. \& Albert, M. J. (1999). Evaluation of pulsed-field gel electrophoresis for typing of Shigella dysenteriae type 1. J Med Microbiol 48, 781-784.

Talukder, K. A., Dutta, D. K., Safa, A. \& 7 other authors (2001). Altering trends in the dominance of Shigella flexneri serotypes and emergence of serologically atypical $S$. flexneri strains in Dhaka, Bangladesh. J Clin Microbiol 39, 3757-3759.

Talukder, K. A., Islam, M. A., Dutta, D. K., Hassan, F., Safa, A., Nair, G. B. \& Sack, D. A. (2002). Phenotypic and genotypic characterization of serologically atypical strains of Shigella flexneri type 4 isolated in Dhaka, Bangladesh. J Clin Microbiol 40, 2490-2497.

Talukder, K. A., Islam, Z., Islam, M. A., Dutta, D. K., Safa, A., Ansaruzzaman, M., Faruque, A. S. G., Shahed, S. N., Nair, G. B. \& Sack, D. A. (2003a). Phenotypic and genotypic characterization of provisional serotype Shigella flexneri $1 \mathrm{c}$ and clonal relationships with 1a and 1b strains isolated in Bangladesh. J Clin Microbiol 41, $110-117$

Talukder, K. A., Islam, M. A., Khajanchi, B. K. \& 7 other authors (2003b). Temporal shifts in the dominance of serotypes of Shigella dysenteriae from 1999 to 2002 in Dhaka, Bangladesh. J Clin Microbiol 41, 5053-5058. 
Tenover, F. C., Arbeit, R. D., Goering, R. V., Mickelsen, P. A., Murray, B. E., Persing, D. H. \& Swaminathan, B. (1995). Interpreting chromosomal DNA restriction patterns produced by pulsed-field gel electrophoresis: criteria for bacterial strain typing. J Clin Microbiol 33, 2233-2239.

Vargas, M., Gascon, J., Jimenez De Anta, M. T. \& Vila, J. (1999). Prevalence of Shigella enterotoxins 1 and 2 among Shigella strains isolated from patients with traveler's diarrhea. J Clin Microbiol 37, 3608-3611.
Victora, C. G. S., Huttly, S. R., Fuchs, S. C. \& 14 other authors (1993). International differences in clinical patterns of diarrhoeal deaths: a comparison of children from Brazil, Senegal, Bangladesh and India. J Diarrhoeal Dis Res 11, 25-29.

World Health Organization (1987). Programme for control of diarrhoeal disease. In Manual for Laboratory Investigation of Acute Enteric Infections, CDD/83.3, Rev. 1. Geneva: World Health Organization. 